\section{Early Primary Duodenal Carcinoma Success- fully Treated by Endoscopic Polypectomy}

An 86-year-old woman presented with marked fatigue, loss of appetite, moderate nausea, and vague epigastric discomfort. The abdominal examination revealed a small umbilical hernia and mild abdominal distension. At upper gastrointestinal endoscopy we found only a small semipedunculate polyp ( $5 \mathrm{~mm}$ in diameter) in the duodenal bulb, with an 8 -mm long stalk emerging from a macroscopically normal mucosa (Figure 1). The biopsy of the polyp showed a well to moderately differentiated adenocarcinoma with invasion limited to the mucosal layer, arising in an adenomatous mucosa (Figure 2). Abdominal ultrasonography and CT excluded primary pancreatic cancer and metastatic liver disease. We planned an endoscopic polypectomy. In order to avoid not being able to complete the diagnosis as a consequence of accidental loss of the small polyp, we took other specimens (from the polyp and the surrounding mucosa) before the polypectomy. As feared, we were not able to retrieve the polyp, since it disappeared into the distal duodenum immediately after the polypectomy. The histological examination of the biopsies taken from the polyp showed tags of adenomatous mucosa with foci of adenocarcinoma, along with edema and congestion of the lamina propria mucosae, while the mucosa in the proximity of the polyp was normal. Given the age and poor surgical outcome, we decided to avoid even limited resection. At follow-up $(3,6,12$, and 24 months later), the patient was well, and neither endoscopy nor biopsy were able to show any lesion in the duodenum.

Primary duodenal carcinomas usually can be recognized at endoscopy as polypoid lesions, sometimes pedunculated, or with a depressed surface and superficial erosions (1); in some cases, they can show the features of a submucous tumor with an ulcer on the surface (2), of partially depressed lesions (very similar to early gastric cancer type Ila- IIc (3), or of an ulcerlike lesion (4). Early carcinoma originating in the duodenal bulb is a recent observation: in a 1992 review, 40 cases were reported in the Japanese literature. of which 14 were completely excised via endoscopic resection (5). The present case was one of completely successful endoscopic treatment of an early duodenal bulb adenocarcinoma, the first published in Europe to our knowledge, in which the lesion presented as a small and negligible polyp.

\section{Tringali, S. Crotta, C. Bodrato, R. Lolli, C. Cerrato, G. Cerrato}

Unit of Gastroenterology and Digestive Endoscopy, Ospedale Regionale della Valle d'Aosta, Aosta, Italy

\section{References}

1. Obata $S$, Suenaga $M$, Araki $K$ et al.: Use of strip biopsy in a case of early duodenal cancer. Endoscopy 1992: 24: 232-234.

2. Kojima $Y$, Kobayashi $T$, Note $M$ et al,: A case of duodenal carcinoma presenting as a submucosal tumor. Surg Today 1992: 22: $357-$ 362 .

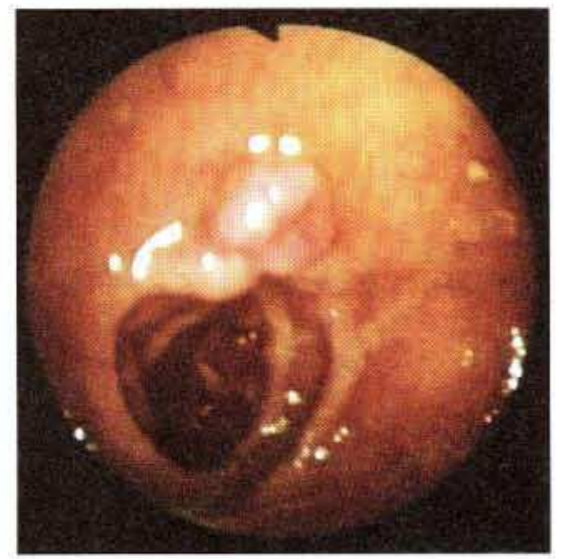

Figure 1:

A patient with an early primary duodenal carcinoma: a small, thin, semipedunculate polyp emerging from a normal mucosa.

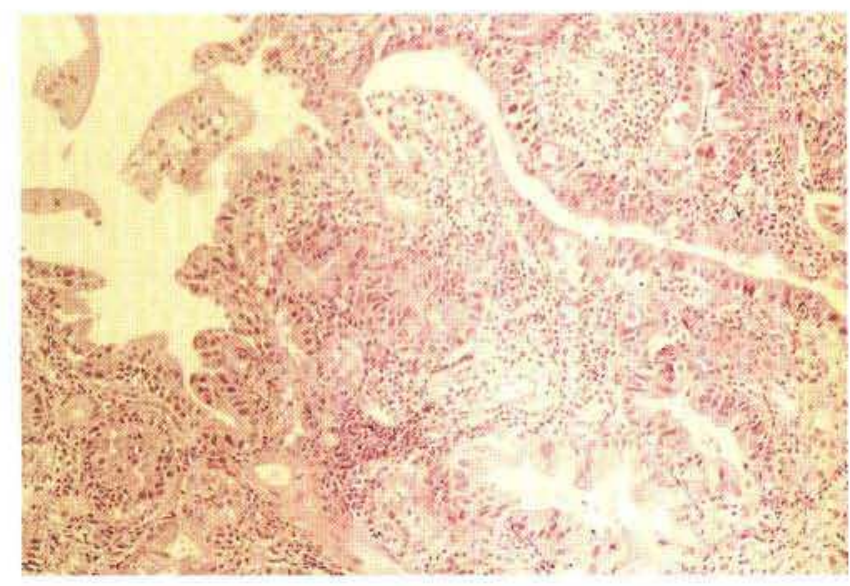

Figure 2: Histology specimen (hematoxylin-eosin and periodic acid-Schiff, magnification $\times 400$ ), showing tags of adenomatous duodenal mucosa with foci of adenocarcinoma, along with edema and congestion of the lamina propria mucosae.

3. Yanagie $H$, Imai $H$, Tani $T$, Ogata $M$ : A case of primary early duodenal cancer. Gan No Rinsho Jpn J Cancer Clin 1990; 36 (I1): 2063-2066.

4. Kusin NM, Biriukov AL: Primary cancer of the duodenum in a young patient occurring under the mask of peptic ulcer. Khirurgiia (Moscau) 1991; 4: 146-147.

5. Takeshita $K$, Watanuki $S$, Goseki $N$ et al.: An endoscopically resected case of early carcinoma of the duodenal bulb. Dig Endose 1992; 4: $261-266$.

\section{Corresponding Author}

M. Tringali, M.D., Unità Operativa di Gastroenterologia ed Endoscopia Digestiva, Ospedale Regionale della Valle d'Aosta, viale Ginevra 3, 11100 Aosta, Italy 